\title{
Features of structural formation and properties of technogenic raw materials in construction material production
}

\author{
Yury Konstantinovich Rubanov, \\ Yulia Egorovna Tokach, \\ Evgeni Ivanovich Evtushenko \\ BSTU named after V.G. Shoukhov \\ Belgorod, Russia \\ yrubanov@yandex.ru, tokach@bk.ru
}

\begin{abstract}
The paper reveals regularity in solid phase materials property change depending on their capability of structural changes. A classification of technogenic waste is proposed that takes into account the condition of their production (biogenic, chemogenic, pyrogenic and mechanogenic) and nature of structural and property changes. Technogenic wastes may serve and are already serving as a source of raw materials for industry. Recommended waste conversion technology for production of construction materials is given for each group of waste. As an example, a possibility of pyrogenic waste conversion and recovery that takes into account the structural instability of the materials is shown. In this case, the structure may be stabilized by a corresponding method of primary processing or the existing structural instability may be used in the composite synthesis technology. A rational recovery scheme that influences the structure of the material is proposed for chemogenic waste in the form of galvanic sludge. Recovery of galvanic sludge may proceed both with and without extraction of metals as additional product.
\end{abstract}

Keywords- classification of wastes, structural changes, reactivity, galvanic sludge

\section{INTRODUCTION}

Construction material production technology includes direct changes of structure, composition and properties of raw materials and intermediate products. Formation of principal properties of a composite material (its strength, durability) finishes at this stage [1-3]. Factory waste may serve as a raw material for diverse branches of industry; however, currently, it is underused. Analysis of using factory waste as recyclable material and production of end-use products show that as late as 2000 only $7.4 \%$ of Class I wastes were recovered in Russia, for Class II the figure is $26.8 \%$, for Class III it is $9.5 \%$ and for Class IV it is $17.8 \%$. Implementation of modern rational approaches to sustainable development is impossible for chemical and smelting enterprises without integrated use of available resources, accompanied by development and implementation of low-waste or waste-free technologies [4, 5].

In this regard, a need arises to take into account structural and phase conversion of technogenic raw materials at its processing stages with the aim to obtain reliable building structures.

\section{PROCEDURE}

On the assumption of fundamental understanding of properties of crystals, the authors revealed certain regularities, linking the degree of structural deformation to structural changeability of solid bodies (Fig. 1) [6].

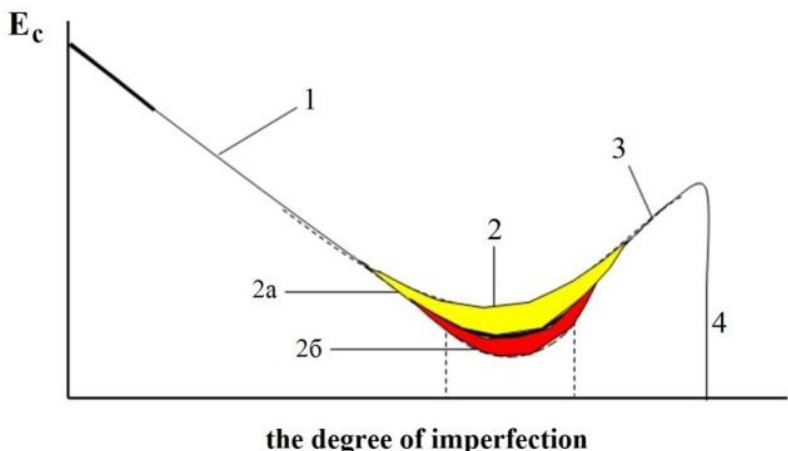

Fig. 1. Characterization of solid-phase materials by their structural changeability: 1 - crystalline materials; 2 - doped materials; $2 \mathrm{a}$ - doped materials in a stable state; 26 - doped state under Hedwall effect or Rehbinder effect; 3 - amorphous (meta-stable) materials; 4 - area of unstable state. $\mathrm{E}_{\mathrm{C}}-$ energy needed for structural changes.

Thus, the potential structural changeability that may be defined through energy, necessary for such changes, serves as a measure of activity or reactivity of the material.

\section{MAIN PART}

The proposed dependency allows monitoring changes in properties of solid bodies, from an ideal crystal characterized by the maximum dislocation formation energy to complete amorphization. The minimum value of dislocation formation energy characterizes the amophization degree of the substance. An unstable state is characterized by a steep drop of dislocation formation energy to zero.

Large-scale introduction of technogenic products into manufacturing requires development of waste classification that take into account not only formation conditions, but structural and property changes as well. Such classifications may be used to determine recommended technologies of 
construction materials for each of the technogenic product groups.
Table 1 shows a classification of technogenic waste which are divided into 4 groups depending on formation conditions.

TABLE 1. Classification of inorganic technogenic waste by formation condition

\begin{tabular}{|c|c|c|c|c|}
\hline \multirow{2}{*}{ Parameters } & \multicolumn{4}{|c|}{ Technogenic waste } \\
\hline & Biological & Chemical & Pyrogenous & Mechanical \\
\hline $\begin{array}{l}\text { Origin of the } \\
\text { waste } \\
\text { (technogenesis) }\end{array}$ & Products of life & $\begin{array}{l}\text { Products of chemical or } \\
\text { physico-chemical } \\
\text { transformations }\end{array}$ & Products of thermal transformations & $\begin{array}{l}\text { Products of mechanical or } \\
\text { hydromechanical effects }\end{array}$ \\
\hline $\begin{array}{l}\text { Types of } \\
\text { dispersed systems }\end{array}$ & $\begin{array}{l}\text { Suspensions and } \\
\text { sols: slurries and } \\
\text { sludges }\end{array}$ & $\begin{array}{l}\text { Suspensions and sols: } \\
\text { crystalline hydrates and } \\
\text { amorphous formations } \\
\text { (galvanic sludges) }\end{array}$ & $\begin{array}{l}\text { Solid heterogenous systems: crystalline } \\
\text { and amorphocrystalline materials } \\
\text { (smelter slags, ash slags, pyrites cinder, } \\
\text { phosphoric slags) }\end{array}$ & $\begin{array}{l}\text { Solid heterogenous } \\
\text { systems, suspensions (by- } \\
\text { produced rocks, tailings, } \\
\text { siftings) }\end{array}$ \\
\hline Dispersion & \multicolumn{2}{|c|}{$\begin{array}{l}\text { Ultramicroheterogeneous (particles 1-100 nm) } \\
\text { and microheterogeneous (particles } 0,1-10 \mu \mathrm{m} \text { ) } \\
\text { systems }\end{array}$} & $\begin{array}{l}\text { Mainly, microheterogeneous and } \\
\text { coarsely dispersed solid systems (grains } \\
\text { or units larger than } 0,1 \mu \mathrm{m} \text { ) }\end{array}$ & $\begin{array}{l}\text { Microheterogeneous and } \\
\text { coarsely dispersed systems }\end{array}$ \\
\hline $\begin{array}{l}\text { Factors, causing the } \\
\text { structural instability } \\
\text { of waste }\end{array}$ & \multicolumn{2}{|c|}{$\begin{array}{l}\text { Aggregative instability, connected with } \\
\text { coagulation processes, and structural instability, } \\
\text { caused by transition from coagulation structures } \\
\text { to condensation and crystallization structures }\end{array}$} & $\begin{array}{l}\text { Structural instability, caused by the } \\
\text { thermal history of the waste - phase } \\
\text { transitions, synthesis of new formations, } \\
\text { rates of heating and cooling etc. }\end{array}$ & $\begin{array}{l}\text { Structural instability, } \\
\text { caused by rock formations } \\
\text { genesis, mechanic } \\
\text { activation of materials }\end{array}$ \\
\hline
\end{tabular}

Biogenic and chemogenic wastes have similar technological characteristics due to formation of a fine structure with high water retentivity. Recovery efficiency of these highly reactive materials declines considerably due to significant structural changes linked to transition from coagulation structures to crystalline ones. Such transition may be accompanied with significant contraction and general deterioration of physical and mechanical properties of end products. Thus, special methods of processing are required for biogenic and chemogenic products in a number of cases, e.g., hydrothermal or thermal treatment; otherwise, they may be used as a reactive additive to the traditional technologies with strict control of dosage. In the latter case hydrothermal synthesis (silicate concretes) or baking (e.g., Portland cement clinker, pottery) are optimal.

During the industrial production a whole range of technogenic waste is produced, one of their defining characteristics is presence of amorphous components. These wastes are extremely diverse in their composition and properties, thus an individual set of methods shall be found for treatment and recovery of each suspension. The most common way of treatment is a combination of thermal treatment and burial, which is inefficient for large-scale wastes and creates additional environmental issues. Use of sludges in building material production appears as a more efficient method. However, a number of common properties of sludges shall be highlighted: high water retentivity; presence of coagulation structures impairing precipitation and compaction; low technological producibility of the sediments after removal of water by filtration (due to high viscosity); quality deterioration of a number of composites after introduction of fine sludges.

Microscopic studies of such sludges have shown that in most cases they are amorphous-crystalline conglomerates. Amorphous component (with high water retentivity) usually consists of calcium, iron or aluminum hydroxides, which are used as coagulating agents, as well as some polymer compounds (flocculating agents) etc.
It has been found out that such structures provide high reactivity of the material, but their use in construction materials production often leads to radical strength loss. An increase of physical and mechanical indicators of the composites may be provided only by hydrothermal treatment or baking, that is, in cases where formation of the construction material goes through creation of a secondary activated structure in the amorphous compound, which is directly linked to loss of physical and crystallization water.

Thus, it is fair to assume that changes in primary processing of fine sludges may allow for production of high-quality construction materials and building products on their basis. Two of the most efficient approaches to sludge waste treatment may be implemented:

1. Use of structural instability and high reactivity of fine sludges directly during the production of the construction materials. However, efficient use of sludges is possible only in technologies that include autoclave treatment or baking. The amount of sludge used as an additive shall be limited.

2. Preliminary thermal or hydrothermal stabilization of sludges radically expands their applicability. Having undergone such treatment they may be used in concretes that harden under normal conditions. The sludge content of composite compounds may be increased significantly as well. Due to high water content in this type of waste, a preliminary hydrothermal treatment appears as the most efficient.

While resolving the issue of sludge use in construction materials production it is especially important to correctly select the primary processing technology. Wrong chose of technology may render the whole process unprofitable.

Studying of waste conditioning and treatment technologies, as well as our own research allowed to propose a set of simple and efficient processes:

1. Increasing the concentration of waste with the help of cesspools (sometimes with coagulation and flocculation agents).

2. Direct use of concentrated sludges in construction materials production processes (as a part of ceramic slips, $40 \%$ water sludges for portland cement clinker production, in plastic 
and semi-dry technologies of clay and silicate brick production with water content of 8-20\%). Water content of the sludges is selected at such a level that it provides necessary plasticity and stability of the suspension, namely $50-90 \%$. At that, sludge water replaces the process water employed within a regular process.

As the research has shown, the most efficient way is to use sludges and concentrated suspensions in floor tile production. Formulation of the ceramic slip is adjusted in such way that it contains about $3-4 \%$ of highly reactive amorphous-crystalline structures, which makes no impact on the plasticity and stability of the slip and improves the quality of the end product.

As a result of the activities undertaken, the waste treatment facilities load was reduced, consumption of fresh water significantly decreased, along with waste water amount and water treatment reagent consumption. Export of sludges to dumps was stopped and a significant saving of valuable mineral raw material was achieved.

Thus, rejection of intensive water removal from the sludges may allow for solution of waste recovery and reuse issues without significant capital costs by using them in wet and semi-dry construction material production processes.

Instability of mechanogenic waste is influenced not only by condition of its formation, but by characteristics of its transportation and storage in dumps and tailing ponds. Finer and lighter components of the same composition are often collected at one location, while heavier compounds are stored at a different location. In this case, simple stack blending applied to the waste may be a solution: mixing of materials taken from certain points of a tailing pond.

Differences in structural instability (activity) of such wastes may be due to rock genesis or due to an activation process, if fine crushing is used. Grinding conditions shall be taken into account in such cases: dry grinding or wet grinding.

The wet grinding is most common in production of different ceramics and refractory concretes [7]. That process is employed in concentrated bonding ceramic suspensions technology. Due to Rehbinder effect, the water conditions lead to changes in activity of the material during its milling, mainly by means of increased specific surface. Intrinsic energy of the material linked to formation of deformation structures is even lower in such case due to relaxation processes during dispergation. In case of intensive wet grinding, some components may reach nanodisperse state, thus significantly altering the properties of the technogenic raw material. In some cases, it may come close to the properties of high-dispersity materials of chemical and biological genesis.

In case of dry grinding, especially in equipment that provides highly intensive structure destruction (jet pulverizers, disintegrators, vibrating mills) the increase in specific surface is accompanied with a rising imperfection of the material and increased structural instability [8].

Pyrogenic wastes are characterized by a complex instability of their properties. It includes not only fluctuations of chemical and mineral composition which are easily solved with homogenization, but also significant differences in reactivity due to structural instability as well.
By that case it is necessary to apply corresponding primary processing or employ existing structural instability in the composite compound synthesis technology.

Pyrogenic wastes are classified with considerations for instability of their content into stable crystalline, activated crystalline, glassy crystalline and structurally meta-stable glassy materials. Conditions of primary and secondary processing define the possibility to obtain such materials $[9,10]$.

Phase composition of the materials obtained may be either predominantly glassy or predominantly crystalline. At that, their reactivity may in some cases be the same. For instance, binding properties (hydraulic activity) of granulated glassy slag and devitrified pumice may be comparable.

Possibility of thermal activation of wastes from hightemperature technologies is better to examine through the example of smelter slags which are rather diverse in their chemical and mineral composition All the methods of molten slag processing may be divided into five groups: granulation, bloating, teeming and crystallization, fiberization, smelting for secondary product.

During the slag processing into any type of product it is necessary to take into account those activation processes that arise during its cooling, they may have significant influence over slag reactivity and properties of end-product construction materials. From the point of view of thermal activation studies, the most attention shall be paid to two most common methods, namely, granulation and teeming and crystallization. In the first case, the slag may be converted to vitreous granules by shock chilling with water, steam or air. In the second case, a crystalline structure is formed in the slag as a result of slow cooling. In a number of cases combined methods may be employed, e.g., natural cooling with subsequent water cooling. At that, it is necessary to consider possible influence of the environment of the structural formation process. Thus, impact of water may be quite significant due to Rehbinder effect, especially at relatively low temperatures.

Until presently, activity of slags including hydraulic activity was defined mainly by their chemical and phase composition. However, in case of the most favorable chemical composition neither fast-cooled vitreous nor slow-cooled crystalline slags show almost no reactivity with water, i.e., they do not solidify.

Structural instability takes a center stage in influence over properties of slags with similar chemical and mineral composition.

The main causes of structural instability in pyrogenic products are:

1. Crystallization, especially pre-crystallization processes typical of slag glasses. This phenomenon is satisfactory studied, because in a number of cases researcher determine optimal crystalline content in glass with the aim to obtain the maximum hydraulic activity of slag-containing binders.

2. Decay of metastable phases. At the moment of the decay, maximum structural mobility may be observed, i.e. maximum activity of the material.

3. Synthesis of growth due to thermochemical reactions. This phenomenon may be seen before the recrystallization and deactivation processes commence. In this case, formation of non-stoichiometric compounds is possible, which do not correspond to an equilibrium composition. Such non-equilibrium composition is the most characteristic of fines from high- 
temperature technologies (especially for high-speed baking), while for smelter slags it is observed only in case of targeted changes of chemical and mineral composition of the waste at the primary processing stage, e.g., by introduction of additives to increase the slag's lime factor.

4. Polymorphic transformation of crystalline phases and residual structural tension are formed due to this shift. Polymorphic transformation of dicalcium silicate (felite) causing silicate decay of basic and highly basic slags may serve as an example.

5. Sulfidic and lime decay of pyrogenic products is due to action of water and formation of reaction products whose volume significantly exceeds that of the initial phases. At that, lime in the slag is usually at different stages of dead burning, thus under natural conditions such decay may take a significant amount of time.

Influence of the abovementioned causes of structural instability over the properties of the waste may significantly vary depending on conditions during the thermal transformations, heating and cooling gradients etc.

Consideration of structural and phase instability of pyrogenic products, in particular that of smelter slags, allows for significant control over physical, chemical and technological properties of the material starting from the primary processing stage, thus regulating the quality the construction materials obtained. These issues shall be resolved by selection of an effective processing and recovery technology appropriate for each individual case. At that, environmental safety of both process and end product shall not be overlooked.

Thus, by defining structural characteristics of technogenic materials, their changeability and formation conditions, a direction of processing may be determined in such a was that ensures stabilization of properties of the recovered technogenic materials.

Figure 4 shows an example waste processing scheme for chemogenic galvanic sludges with action onto the microstructure of the material. Recovery of galvanic sludge may proceed both with and without extraction of metals as additional product. $[11,12]$.

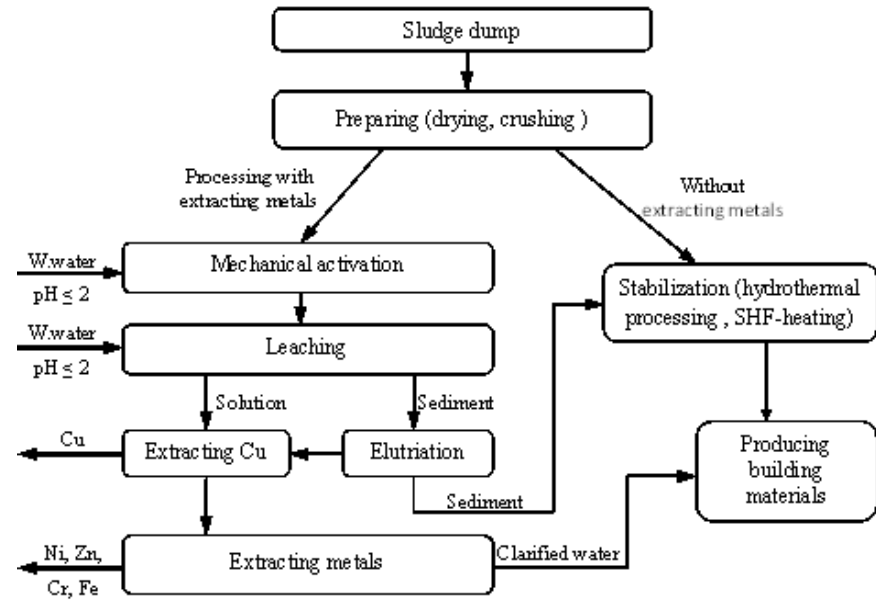

Fig. 2. Processing scheme for chemogenic wastes (sludges and waste water from galvanic manufacturing)
Intensification of metal extraction from the slags is achieved by application of mechanical and chemical activation of suspensions consisting of milled solids and waste waters of similar composition with lowered acidity, that facilitate formation of water-soluble metallic compounds and subsequent desalination and selective extraction of valuable components.

The process scheme includes the slag blending area, mechanical and chemical activation in the wet-grinding disintegrator together with an active medium, desalination reactor for water-soluble compounds and extraction of metallic ions by electrofloatation with flotation reagents and collectors (Fig. 3).

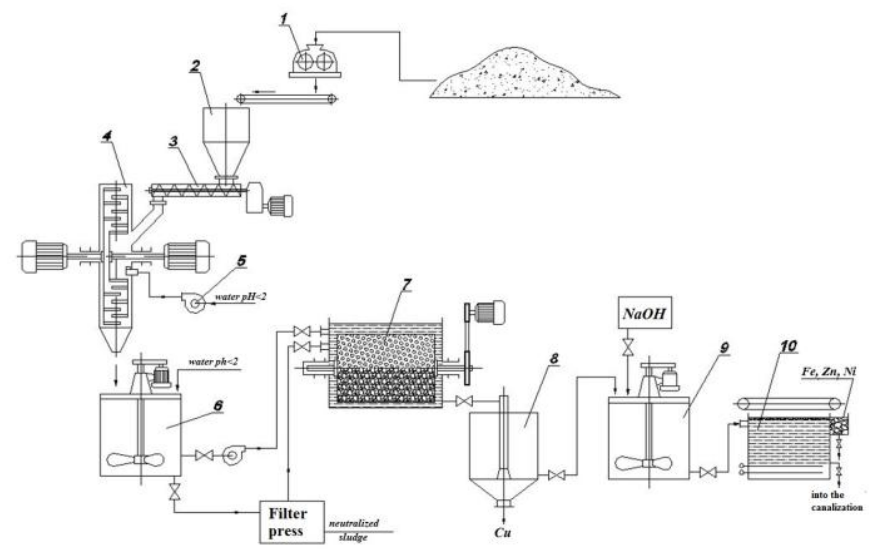

Fig. 3. Process scheme for galvanic sludge processing: 1 - two-roll crusher; 2 - temporary storage bunker; 3 - screw feeder; 4 - wet grinding disintegrator; 5 - pump; 6 - desalination reactor; 7 - Cu extraction unit; 8 - sediment tank; 9 $\mathrm{pH}$ adjustment tank; 10 - electrofloatation unit.

Processing of galvanic sludges without extraction of metals or further processing of sediments after the extraction includes stabilization of the material to relax structural tensions. The stabilization is performed by means of hydrothermal treatment or by heating. The material stabilized in such way may be used as a feed component for construction material production, namely: as an additive to feed paste for production of bricks, roof tiles, concrete mixtures and bituminous concretes [13].

A wide variety of solid wastes and vast difference in their composition makes the task of their recovery significantly harder, in a number of cases making it necessary to look for new solutions that take into account not only chemical and mineral composition of the waste, but its activity as well. Such approaches to complex reclamation of industrial waste allows for organization of large-scale processing of chemically diverse bulk technogenic waste materials. It is possible to obtain a diverse range of products by applying a set of simple conditioning and processing methods, specifically selected for a certain material. In this case, it is possible to predict properties of not just wastes, but materials manufactured from the wastes. Arrangement of centralized processing, especially if linked to a large consumer of waste material, will increase profitability of the process.

\section{CONCLUSIONS}

The authors showed that solid phase transformations may be considered as processes directly defined and regulated by the structural dynamics, while activity of the materials may be 
evaluated from their potential structural changeability. An example of a rational scheme for chemogenic waste reclamation is proposed in the form of galvanic sludge processing influencing the structure of material.

\section{References}

[1] I.A. Ryibev, Stroitelnoe materialovedenie [Construction-related Material Science], Vyisshaya shkola, 2002.

[2] V. Hasik, J. P. S. Chhabra, G. P. Warn, "Investigation of the Sustainability and Resilience Characteristics of Buildings Including Existing and Potential Assessment Metrics", Resilience of the Integrated Building, pp. 1019-1033, April 2017 [Architectural Engineering National Conference (AEI), 2017].

[3] H. Schmalzried, Chemical Kinetics of Solids, Gardners Books, 2007.

[4] V.N. Anisimov, "Bezothodnaya pererabotka prirodno-tehnogennyih mestorozhdeniy mobilnyimi tehnologicheskimi kompleksami " [Nonwaste processing of natural and technogenic stocks by mobile technological stacks], Gornaya promyishlennost, vol. 4, pp. 35-402009

[5] Kulczycka, Joanna; Kowalski, Zygmunt; Smol, Marzena, "Evaluation of the recovery of Rare Earth Elements (REE) from phosphogypsum waste - case study of the WIZOW Chemical Plant (Poland)", Journal of Cleaner Production, vol. 113, pp. 345-354, February, 2016.

[6] E.I. Evtushenko, Aktivatsionnyie protsessyi v tehnologii stroitelnyih materialov [Activation Processes In Construction Material Technology], Belgorod: BGTU Press, 2003, pp 14-22.

[7] B.K. Kara-Sal, "Strukturnyie izmeneniya materiala $\mathrm{v}$ tehnologii keramiki" [Structural Changes In Materials of Ceramics Technology], Vestnik TGU, vol. 3, pp. 37-40, 2012.

[8] V.A. Arsentev, L.F. Bileko, L.A. Vaysberg, "Mehanicheskaya aktivatsiya mineralno-organicheskih poroshkov na vibratsionnoy melnitse" [Mechanical Activation of Mineral and Organic Powders With Vibration Mill], Obogaschenie rud, vol. 5, pp. 3-6, 2006.

[9] N.P. Kudeyarova, M.A. Gostischeva, "Gidratatsionnaya aktivnost mineralov staleplavilnyih shlakov v avtoklavnyih usloviyah" [Hydration Activity of Smelter Slag Minerals in Digesters] Stroitelnye Materialy, 2007, vol. 8, pp. 34-36.

[10]E.I. Shmitko, M.V. Titova, "Upravlenie strukturoy dispersnozernistyih materialov s uchetom dispersnosti i vnutrennih sil " [Control of Structure of Granular Particulate Materials With Considerations For Grade of Dispersion And Internal Forces], Stroitelnyie materialyi, vol. 8, pp. 72-74, 2007

[11]Pat 2422543 Russian Federation, Sposob pererabotki shlamov galvanicheskogo proizvodstva [A Method Of Galvanic Sludge Processing], Rubanov Yu. K., Tokach Yu. E.; published 27.06.2011

[12] Yu. E. Tokach, Yu.K. Rubanov, N.A. Pivovarova, L.N. Balyatinskaya, Galvanic sludge recycling with the extraction of valuable components. Middle-East Journal of Scientific Research, 2013, pp. 1646-1655.

[13] H. Yuehui, C. Libao, H. Baiyun, P. Liaw, Recycling of heavy metal alloy turnings to powder by oxidation-reduction process. International Journal of Refractory Metals and Hard Materials, 2003, pp. $227-231$. 
